\title{
Fuzzy Fractional-Order PID Controller for Fractional Model of Pneumatic Pressure System
}

\author{
M. Al-Dhaifallah $\mathbb{D},{ }^{1,2}$ N. Kanagaraj, ${ }^{1}$ and K. S. Nisar $\mathbb{D}^{3}$ \\ ${ }^{1}$ Electrical Engineering Department, College of Engineering at Wadi Addawasir, Prince Sattam Bin Abdulaziz University, \\ Wadi Addawasir, Saudi Arabia \\ ${ }^{2}$ Systems Engineering Department, King Fahd University of Petroleum and Minerals, Dhahran, Saudi Arabia \\ ${ }^{3}$ Department of Mathematics, College of Arts \& Science at Wadi Addawasir, Prince Sattam Bin Abdulaziz University, \\ AlKharj, Saudi Arabia \\ Correspondence should be addressed to K. S. Nisar; ksnisar1@gmail.com
}

Received 22 June 2017; Revised 8 January 2018; Accepted 30 January 2018; Published 28 February 2018

Academic Editor: Hung-Yuan Chung

Copyright (C) 2018 M. Al-Dhaifallah et al. This is an open access article distributed under the Creative Commons Attribution License, which permits unrestricted use, distribution, and reproduction in any medium, provided the original work is properly cited.

\begin{abstract}
This article presents a fuzzy fractional-order PID (FFOPID) controller scheme for a pneumatic pressure regulating system. The industrial pneumatic pressure systems are having strong dynamic and nonlinearity characteristics; further, these systems come across frequent load variations and external disturbances. Hence, for the smooth and trouble-free operation of the industrial pressure system, an effective control mechanism could be adopted. The objective of this work is to design an intelligent fuzzy-based fractional-order PID control scheme to ensure a robust performance with respect to load variation and external disturbances. A novel model of a pilot pressure regulating system is developed to validate the effectiveness of the proposed control scheme. Simulation studies are carried out in a delayed nonlinear pressure regulating system under different operating conditions using fractional-order PID (FOPID) controller with fuzzy online gain tuning mechanism. The results demonstrate the usefulness of the proposed strategy and confirm the performance improvement for the pneumatic pressure system. To highlight the advantages of the proposed scheme a comparative study with conventional PID and FOPID control schemes is made.
\end{abstract}

\section{Introduction}

Pneumatic pressure is one among the vital variables used in industries like power plants, chemical reaction control, pneumatic position servo systems, well drilling, heating, ventilating and air conditioning systems, automobile, and so on. The dynamic characteristics of pneumatic pressure plants are highly nonlinear due to the compressibility of air, load variations, and external disturbances. Further, the industrial pneumatic pressure plants are usually interconnected and operating at different pressure level. Therefore, the precise control of pressure plant is complex due to the presence of uncertainties and nonlinearity. Hence, an efficient control strategy is needed for trouble-free operation of the pneumatic system in industries. The classical PI and PID controllers are widely used in industrial applications in the past because of its advantages. PID control is a simple and effective control method and it can be easily implemented for industrial control applications. However, the PID control algorithm is not advisable for the complex and nonlinear system. On the other hand, the fractional calculus is getting much more attention in the field of control system engineering due to its potential and significant importance [1-3]. The controllers, making use of fractional-order derivatives and integrals, give improved results compared to the classical controllers in terms of robustness [4-6]. Fractional-order (FO) controllers are usually expressed by fractional-order differential equations. The FO controllers are derived from the integer order by adding the fractional powers in integral and derivative terms. For example, in addition to the proportional $\left(K_{P}\right)$, 
integral $\left(K_{I}\right)$, and derivative $\left(K_{D}\right)$ parameters which comprise the integer-order PID, the FOPID controller has two more parameters an integrator order $(\lambda)$ and a differentiator order $(\mu)$. Adding the integral and derivative terms of fractional order will improve system frequency response to be better and leads to design an improved control system [7-10]. The FOPID control scheme has certain merits whereby it offers five parameters to be tuned. However, this control scheme has its own demerits as it makes the system more complex than the classical one.

Recent research trends in FO control are looking towards using fuzzy with FO control scheme to improve the control performances. The rule base fuzzy set theory provides more flexibility in designing complex industrial control system. In fuzzy set theory, linguistic notations are used to express the observations easily to form a control structure. The fuzzy logic controller (FLC) design is becoming simple, even for more complex and nonlinear industrial process without knowledge of the exact mathematical description of the system [11]. Further, FLC is combined with the FO controller for fine-tuning parametric gains and guarantee optimal performance owing to nonlinearities, load disturbances, and plant parameters variations [12-14]. The adaptive method provided by the fuzzy system will improve the dynamic performances of the FO controller through which the controller may respond quickly to parameter variation.

By considering all these aspects, a fuzzy-based FOPID control scheme is proposed for faster response and better control performances. To demonstrate the performances of proposed control technique, a novel pneumatic pressure system model is developed and the system performances are studied under load disturbances and changes in set-point conditions. This paper is organized as follows. In Section 2, the mathematical background of fractional calculus is discussed. Section 3 gives an overview of the experimental setup for pneumatic pressure control system. The modeling of the proposed system is discussed in Section 4. Section 5 describes the controller design for the proposed system. Section 6 presents the simulation results. The findings are given as a conclusion in Section 7 , followed by the references.

\section{Mathematical Background of Fractional Calculus}

Fractional-order calculus (FOC) is one of the popular and emerging mathematics branches that deals with differentiation and integration of real or complex order $[1,2,15]$. The fractional-order calculus provides efficient tools for many situations related to the fractal dimension, infinite memory, and chaotic behavior. Recently, FOC attracted various researchers due to its application in electronics, Bioengineering, control theory, and many more areas [7-10]. Fractional-order mathematical phenomena are very useful to describe and model real-time system more accurately than the conventional integer methods. The fractional-order differentiator can be denoted as a continuous differintegral operator $[1,2,16-18]$, which is given by

$$
a D_{t}^{\gamma}= \begin{cases}\frac{d^{\gamma}}{d t^{\gamma}}, & \Re(\gamma)>0 \\ 1, & \Re(\gamma)=0 \\ \int_{a}^{t}(d \tau)^{-\gamma}, & \Re(\gamma)<0,\end{cases}
$$

where $\gamma$ is the order of the differintegration and $a$ is constant related to initial conditions.

The most commonly used definitions in FOC are Riemann-Liouville (e.g., in calculus), Caputo (e.g., in numerical integration and physics), and Grunwald-Letnikov (e.g., communications and control).

The definitions due to Riemann-Liouville and Caputo are, respectively, given by

$$
\begin{aligned}
& a D_{t}^{\gamma} f(t)=\frac{1}{\Gamma(n-1)} \frac{d^{n}}{d t^{n}} \int_{a}^{t} \frac{f(\tau)}{f(t-\tau)^{\gamma-n+1}} d \tau, \\
& a D_{t}^{\gamma} f(t)=\frac{1}{\Gamma(\gamma-n)} \int_{a}^{t} \frac{f^{(n)}(\tau)}{f(t-\tau)^{\gamma-n+1}} d \tau,
\end{aligned}
$$

where $(n-1<\gamma<n)$ and $\Gamma(\gamma)$ is the familiar gamma function defined by

$$
\Gamma(\gamma)=\int_{0}^{\infty} e^{-u} u^{\gamma-1} d u, \quad \Re(\gamma)>0 .
$$

Here, in this paper the Grunwald-Letnikov definition is used and is expressed by

$$
{ }_{a} D_{\gamma}^{t} f(t)=\lim _{h \rightarrow 0} h^{-\gamma} \sum_{j=0}^{[(t-a) / h]}(-1)^{j}\left(\begin{array}{l}
\gamma \\
j
\end{array}\right) f(t-j h),
$$

where $(n-1<\gamma<n),[(t-a) / h]$ is integer part, and $a, t$ are the limits of operator. The binomial coefficient is evaluated by the gamma function that generalizes the factorial operator:

$$
\left(\begin{array}{l}
\gamma \\
j
\end{array}\right)=\frac{\gamma !}{j !(\gamma-j) !}=\frac{\Gamma(\gamma+j)}{\Gamma(j+1) \Gamma(\gamma-j+1)} .
$$

The equation given in (4) is very useful to obtain a numerical solution of fractional differential equation [19]. 


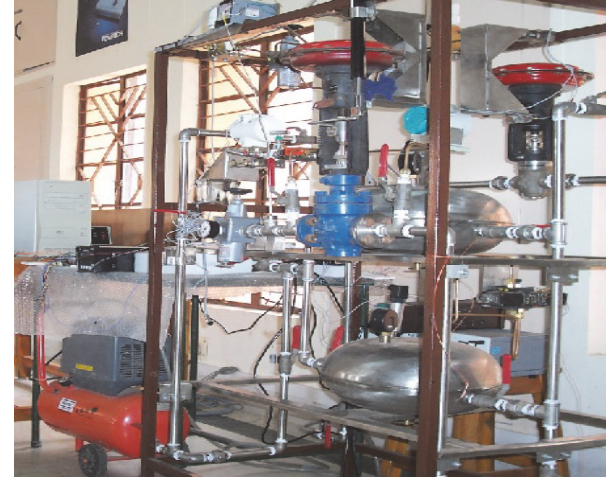

FIGURE 1: Photograph of the pneumatic pressure system.

\section{Pneumatic Pressure Control Experimental Setup}

The experimental setup of the pneumatic pressure control system is shown in Figure 1. It consists of an air compressor, pressure transmitter, pressure regulator, electropneumatic control valve, pressure indicator, and controller interfacing units. Figure 2 depicts the scheme of the pressure control. The air compressor is attached to the pressure regulator, which supplies the air at constant pressure. An equal percentage electropneumatic control valve of $50 \mathrm{~mm}$ size at inlet regulates air flow to the pressure tank. A precise pressure transmitter (PT) attached to the pressure tank measures pressure at each sampling period and gives output as a current signal of 4 to $20 \mathrm{~mA}$. The current signal is converted into a voltage signal in the range of 0 to 5 volts by current to voltage ( $V$ to $I$ ) converter. The controller block of this setup computes tank pressure using input voltage signal and by applying control algorithm the position of the control valve will be manipulated to keep the tank pressure at the desired level. A 32-bit advanced RISC architecture ARM7 (AT91M55800A) microcontroller is used in the controller part. The microcontroller output voltage magnitude is based on the measured and reference values. The controller output voltage is first converted into a current signal of 4 to $20 \mathrm{~mA}$ and then to pressure signal suitably to manipulate the control valve. A pressure indicator (PI) fixed at the top of the pressure tank is used to read the tank pressure manually. Based on the valve characteristics, it is obvious that the pneumatic system possesses inherent nonlinearity and parameters uncertainty because of air compressibility.

\section{Modeling of Pneumatic Pressure System}

The transient method is commonly used in the industrial process to identify the dynamic model of the system. To obtain the system transient response, the process is initially allowed to run for sufficient time to reach the steady state at the normal operating condition. Then, the controller is disconnected from the loop and an open-loop transient is introduced by a step change input signal and the system response is plotted against time. In case of the proposed

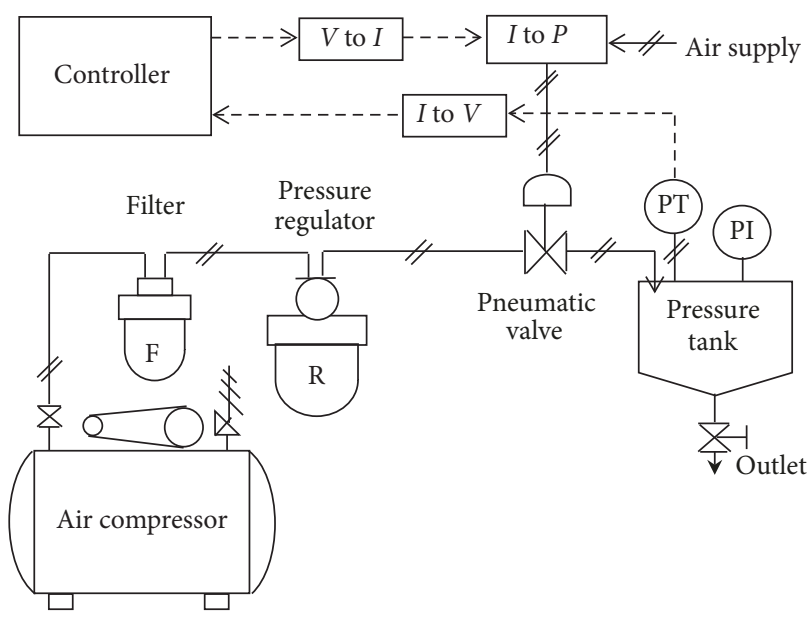

PT: pressure transmitter

PI: pressure indicator

$V$ to $I$ : voltage to current converter

$I$ to $V$ : current to voltage converter

$I$ to $P$ : current to pressure converter

FIGURE 2: Schematic diagram of pneumatic pressure control system.

pneumatic system, an open-loop transient is introduced by a step change input signal to the control valve. The step change to the control valve is conveniently provided from the controller. The input-output data are recorded at a uniform time interval over a period of time and expressed as

$$
\begin{aligned}
& u=[u(t), u(2 t), u(3 t), \ldots, u(N t)] \\
& y=[y(t), y(2 t), y(3 t), \ldots, y(N t)]
\end{aligned}
$$

where $u$ and $y$ are the input and output measured values, $t$ is sampling time, and $N t$ is the time of the final measurement. The time-domain data are measured with a sampling period of $0.1 \mathrm{sec}$. By using the measured time-domain data, the integer-order model of the proposed system is identified by linear ARX regressive system identification method [20]. The identified system model is given in

$$
G(s)=\frac{2.87}{44.6 s^{2}+105.6 s+1} e^{-1.4 s} .
$$

In most of the industrial processes, the standard inputoutput (integer-order) model will be available for experimental study. The system FO model could be obtained easily from the integer-order model. Several tools are available to identify the FO model from the integer-order model. Among them, the Fractional-Order Modeling and Control (FOMCON) toolbox of MATLAB [21] is useful for FO model identification and controller design and optimization. By using FOMCON toolbox, the fractional-order model of the proposed system is identified with Grunwald-Letnikov definition [22] and using the approach described in [23]. To identify the FO model, the fractional-order differential equation is transformed into a fractional-order integral equation. By expanding integral term a least-squares expression is created that allows the implicit time delay term to have an explicit appearance in 
the parameter vector. This supports for simple estimation of model parameters simultaneously with time delay. The resulting model is given in

$$
G(s)=\frac{3.96 s^{0.12}}{133 s^{1.13}+105.6 s+1} e^{-1.4 s} .
$$

\section{Controller Design}

5.1. Integer-Order PID Controller. The selection of the controller parameters and their optimal values is essential to obtain good control. A good controller is supposed to have minimum overshoot, settling time, and robustness to load disturbances. The Ziegler-Nichols (ZN) controller tuning [24] is applied in the proposed system to identify the controller parameters values. The $\mathrm{ZN}$ method is considered to be a better choice for the process of pneumatic pressure control having dead time. In the controller tuning process, three variables, namely, process gain $\left(g_{p}\right)$, dead time $\left(t_{d}\right)$, and time constant $(\tau)$, are calculated from the open-loop timedomain plot. From the calculated values, the controller gain, integral time, and derivative time could be obtained for PID controller using the following expressions:

$$
\begin{aligned}
K_{c} & =\frac{1.2 \tau}{g_{p} t_{d}} \\
T_{i} & =2 t_{d} \\
T_{d} & =\frac{T_{i}}{4} .
\end{aligned}
$$

The calculated values from open-loop experimental data are time delay $t_{d}=1.4 \mathrm{~s}$, process gain $g_{p}=2.87$, and time constant $\tau=52 \mathrm{~s}$. Using (9), the computed values of integer-order PID controller parameters, namely, gain $\left(K_{c}\right)$, integral time $\left(T_{i}\right)$, and derivate time $\left(T_{d}\right)$, are $15.5,2.8$, and 0.7 , respectively.

5.2. Fractional-Order PID Controller. Recent research studies have shown that FO controllers could perform better than conventional (integer-order) controllers in terms of system performance and robustness $[25,26]$. The application of FO calculus for the dynamic system has been started in the year 1960 [27]. Since then the research on FO control was extended to various fields of engineering. The fractionalorder PID controller is a sum of fractional operators along with controller gains. The FOPID controller transfer function representation is expressed as

$$
G_{c}(s)=\frac{u(s)}{e(s)}=K_{P}+K_{I} s^{-\lambda}+K_{D} s^{\mu},
$$

where $G_{c}(s)$ is controller transfer function, $e(s)$ is error, and $u(s)$ is the output. $K_{P}, K_{I}$, and $K_{D}$ are the gains for proportional, integral, and derivative terms. The term $\lambda$ is the fractional component of integral parts and $\mu$ is the fractional component of derivative parts. The FOPID controller timedomain representation is given in

$$
u(t)=K_{P} e(t)+K_{I} D^{-\lambda} e(t)+K_{D} D^{\mu} e(t) .
$$

TABLE 1: Controller parameters of fractional-order PID controller.

\begin{tabular}{ccccc}
\hline$K_{P}$ & $K_{I}$ & $\lambda$ & $K_{D}$ & $\mu$ \\
\hline 6.22 & 0.09 & 0.91 & 0.33 & 1.33 \\
\hline
\end{tabular}

It is evident that, in FOPID controller, apart from the usual three parameters $K_{P}, K_{I}$, and $K_{D}$, the parameters of integralorder $\lambda$ and derivative-order $\mu$ should be considered. Hence, the FOPID controller design procedure consists of solving five nonlinear equations with five unknowns $K_{P}, K_{I}, K_{D}$, $\lambda$, and $\mu$ related to the system. On the other hand, the complexity of the five nonlinear equations is very significant, mainly because of the fractional order. By considering the difficulties, the MATLAB with the suitable tool could be a better choice to design the controller. Further, the MATLAB optimization toolbox gives the best solutions with minimum error. The controller design for the proposed system is made using FOMCON toolbox with Oustaloup's rational approximation technique described in [28, 29]. Further, Nelder-Mead optimization technique [30] with integral of square error (ISE) performance metric is applied to optimize controller parameters. For optimization, the following design specifications are selected.

$$
\begin{aligned}
& \text { Gain margin }=10 \mathrm{~dB} . \\
& \text { Phase margin }=60 \mathrm{deg} . \\
& \text { Sensitivity function: }|S(j \omega)|_{\mathrm{dB}} \leq-20 \mathrm{~dB} \text {, for } \omega \leq \omega_{s}= \\
& 0.01 \mathrm{rad} / \mathrm{s} \text {. } \\
& \text { Noise rejection: }|T(j \omega)|_{\mathrm{dB}} \leq-20 \mathrm{~dB} \text {, for } \omega \leq \omega_{t}= \\
& 10 \mathrm{rad} / \mathrm{s} \text {. }
\end{aligned}
$$

With the help of the optimization indices, the calculated fractional-order controller parameters' values are given in Table 1.

5.3. Fuzzy Fractional-Order PID Controller. The rule base fuzzy set theory gives more flexibility in designing systems and expressing the observations in easy-to-follow linguistic notation. Further, the fuzzy logic system performs better in tuning of controller parameters in closed-loop control system, particularly system with nonlinearity between its inputs and outputs. The classical controllers, including fractionalorder controller work on the basis of the inputs of errors with a fixed gain value for the proportional, integral, and derivative terms. Hence, the controller performance is not up to the expected level for nonlinear and complex system. An attempt can be made to incorporate dynamic gain value for the proportional, integral, and derivative terms instead of a fixed gain. Dynamically modifying the gain in a FOPID control structure will enhance controller performance and bring the system output quickly to stable condition during load variation and external disturbances. By considering these aspects, a fuzzy logic combined with fractional-order control scheme is proposed in this work. The FFOPID controller is a combination of rule base fuzzy control with FOPID controller. In this control strategy, the FLC is designed to use system error and derivative error inputs to obtain the scaling factor of the proportional, integral, and derivative terms. 


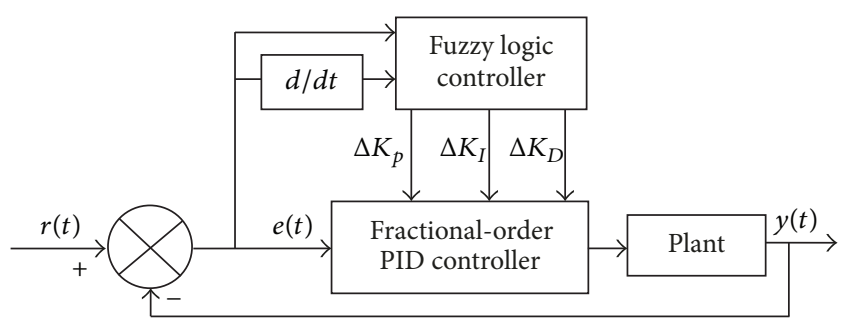

FIGURE 3: Block diagram of the fuzzy fractional-order PID controller.

Using these scaling factors, the controller gain magnitude will be updated at each sampling period. The frame of a typical FFOPID control structure is shown in Figure 3.

In the proposed control structure, the FLC uses the error and derivative error inputs and computes the scaling factor for proportional, integral, and derivative terms and then these values are used to update the gain parameters of FOPID controller. So, the final gain values of $k_{P}, k_{I}$, and $k_{D}$ for FOPID controller are computed from the following expression:

$$
\begin{aligned}
& k_{P}=K_{P}+\Delta K_{P} \\
& k_{I}=K_{I}+\Delta K_{I} \\
& k_{D}=K_{D}+\Delta K_{D},
\end{aligned}
$$

where $K_{P}, K_{I}$, and $K_{D}$ are the initial gain value of FOPID controller and $\Delta K_{P}, \Delta K_{I}$, and $\Delta K_{D}$ are the scaling factors computed from FLC. The triangle membership functions are used for input and output fuzzy sets and Mamdani-type fuzzy inference system is applied. Three membership functions are selected for the inputs and to produce precise output; five membership functions are chosen for the outputs. The membership functions used in the FLC design are shown in Figure 4; the membership functions are designated with linguistic variables NB (negative big), NS (negative small), $\mathrm{N}$ (negative), $\mathrm{Z}$ (zero), $\mathrm{P}$ (positive), PS (positive small), and PB (positive big). The rule base is the vital part of the FLC design and it relates the input and output linguistic variables based on the current input. Mudi and Pal 1999 [30] recommended the methods for framing rule base using intuitive logic. The rule base used for each output is shown in Table 2. The relationship between inputs and output of each case is shown in surface view, in Figure 5. The surface view specifies how the scaling factor value could vary based on the input error and change-in-error magnitude. From the surface view, it is observed that the input and output have a nonlinear relationship, particularly for the proportional and derivative scaling factors. Further, the surface obviously shows that the values of the proportional, integral, and derivative scaling factors are more for larger amplitude of error and change-in-error. Also, these values are gradually reduced for the smaller error and change-in-error values. The center of gravity defuzzification method is selected to determine the crisp output.
TABLE 2: Fuzzy linguistic rule-base and surface view.

(a)

\begin{tabular}{lccc}
\hline$\Delta K_{P}$ & & $\Delta e$ & \\
& $\mathrm{NE}$ & $\mathrm{Z}$ & $\mathrm{P}$ \\
\hline$e$ & & & \\
$\mathrm{NE}$ & $\mathrm{NB}$ & $\mathrm{NS}$ & $\mathrm{Z}$ \\
$\mathrm{Z}$ & $\mathrm{NB}$ & $\mathrm{NS}$ & $\mathrm{NS}$ \\
$\mathrm{P}$ & $\mathrm{Z}$ & $\mathrm{PS}$ & $\mathrm{PS}$ \\
\hline
\end{tabular}

(b)

\begin{tabular}{lccc}
\hline$\Delta K_{I}$ & & $\Delta e$ & \\
\hline$e$ & $\mathrm{NE}$ & $\mathrm{Z}$ & $\mathrm{P}$ \\
$\mathrm{NE}$ & $\mathrm{NB}$ & $\mathrm{NS}$ & $\mathrm{NS}$ \\
$\mathrm{Z}$ & $\mathrm{NS}$ & $\mathrm{Z}$ & $\mathrm{PS}$ \\
$\mathrm{P}$ & $\mathrm{Z}$ & $\mathrm{PS}$ & $\mathrm{PB}$ \\
\hline
\end{tabular}

(c)

\begin{tabular}{lccc}
\hline$\Delta K_{D}$ & & $\Delta e$ & \\
\hline$e$ & $\mathrm{NE}$ & $\mathrm{Z}$ & $\mathrm{P}$ \\
$\mathrm{NE}$ & $\mathrm{NS}$ & $\mathrm{NS}$ & $\mathrm{Z}$ \\
$\mathrm{Z}$ & $\mathrm{Z}$ & $\mathrm{Z}$ & $\mathrm{PS}$ \\
$\mathrm{P}$ & $\mathrm{Z}$ & $\mathrm{PS}$ & $\mathrm{PS}$ \\
\hline
\end{tabular}

\section{Simulation Results}

The closed-loop pneumatic pressure system performance under various control schemes is studied using step input, load disturbances, and set-point change. The unit step response of the pressure control system with conventional PID controller, FOPID controller, and FFOPID controller is shown in Figure 6. From the step response result, the system with conventional controller takes much time to reach the desired output. Also, the output has a reasonable overshoot before reaching the steady-state condition. In case of the system with FOPID controller, the system output reaches desired level faster than conventional control scheme but with a small overshoot. On the other hand, the system with fuzzy logic based fractional controller makes system output settle quicker than conventional PID and FOPID control scheme. Due to the online gain modification in FOPID control scheme using fuzzy logic, the gain factor of proportional, integral, and derivate terms is updated at each sampling time which makes the controller perform better. From the step input simulation results, one can easily say that the FFOPID controller is more suitable for pneumatic pressure regulating system with dead time.

To validate the robustness of controller, load disturbance is introduced at the steady-state condition. Figure 7 shows the system performance under three different control schemes with load disturbance at steady-state condition. It is noticed that the system using FFOPID controller reaches steady state faster than the other two methods because the fuzzy system tracks the load disturbances and the related parameter variation easily and updates the gain parameters in FOPID 


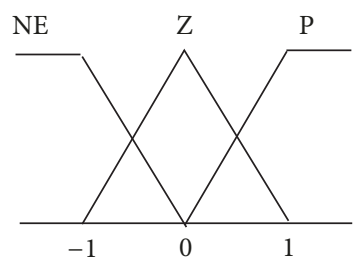

(a) Input (error)

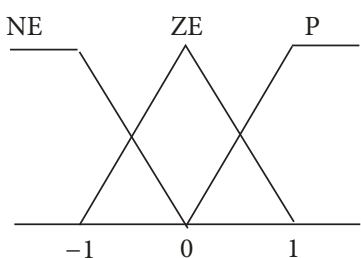

(b) Input (change-in-error)

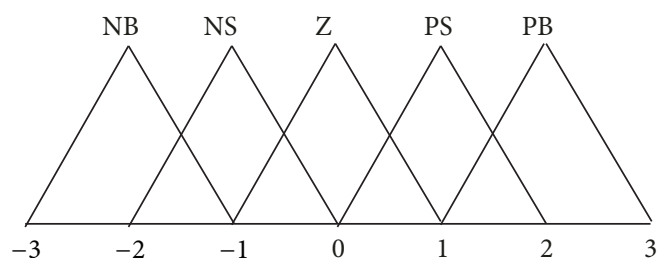

(c) Outputs

FIGURE 4: Fuzzy membership functions.

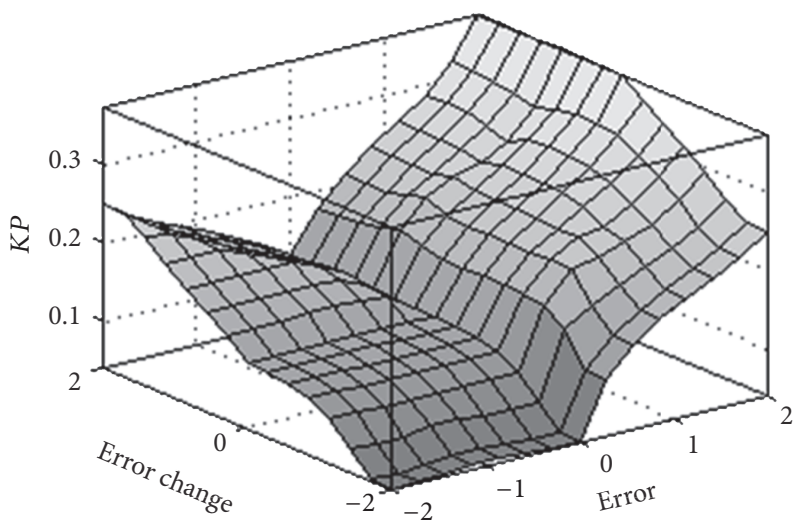

(a) Output $\Delta K_{P}$

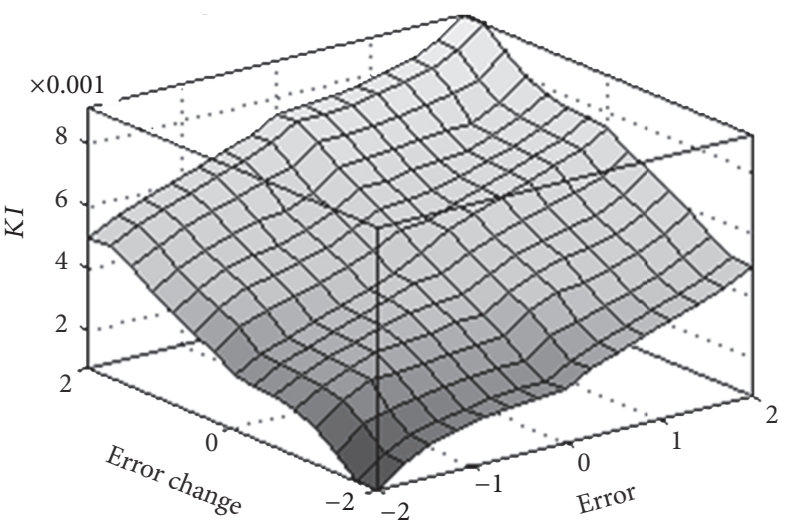

(b) Output $\Delta K_{I}$

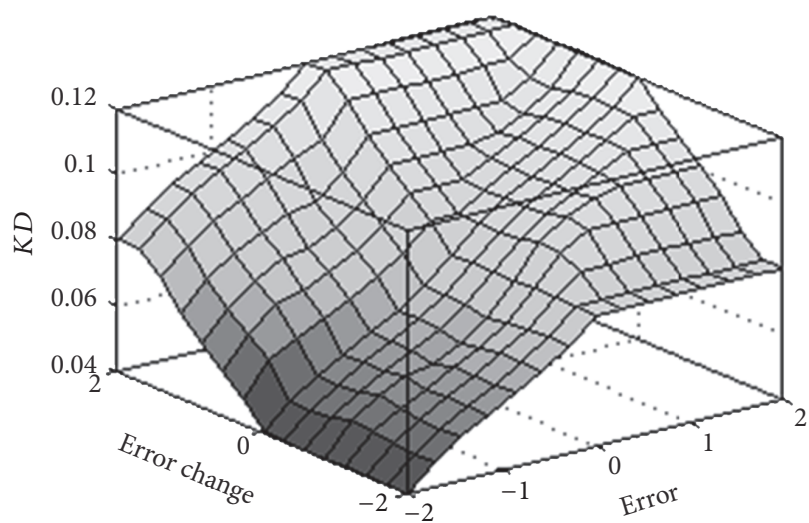

(c) Output $\Delta K_{D}$

FIGURE 5: Surface views for input versus output.

controller block. Figure 8 depicts the relevant control signals corresponding to load disturbance shown in Figure 7.

The controllers' performance for set-point change is also studied for the proposed pneumatic system. The system response and related control signals for three different control structures are shown in Figures 9 and 10. From the results, it is observed that FFOPID control scheme effectively identify the changes in the set point and modify the controller parameters accordingly to make system output reach a new level with the short span of time as compared to other controllers. Numerical comparative analysis of three different control schemes using performance measures such as settling time, overshoot, integral square error (ISE), and integral absolute error (IAE) are given in Table 3. The performance measures in Table 3 evidently depict that the fuzzy logic combined fractionalorder controller outperforms the FOPID and conventional PID controllers in all aspects.

\section{Conclusion}

In this paper, a rule base fuzzy fractional-order PID controller was designed with online gain changing strategy. To demonstrate the proposed control scheme, a pneumatic pressure tank experimental system model has been developed using open-loop experimental data. Using the system model, the controller performances have been demonstrated for step input, under load variation and set-point change conditions. The results evidently showed that the proposed control 
TABLE 3: Numerical comparison of controllers' performance.

\begin{tabular}{lcccc}
\hline Controller & $\begin{array}{c}\text { Settling } \\
\text { Time }\end{array}$ & $\begin{array}{c}\text { Over } \\
\text { shoot }\end{array}$ & ISE & IAE \\
\hline $\begin{array}{l}\text { Fuzzy fractional order PID } \\
\text { controller }\end{array}$ & 7 & $0 \%$ & 2.19 & 3.20 \\
Fractional order PID controller & 12 & $2 \%$ & 2.62 & 3.47 \\
Conventional PID controller & 14 & $6.5 \%$ & 3.12 & 4.07 \\
\hline
\end{tabular}

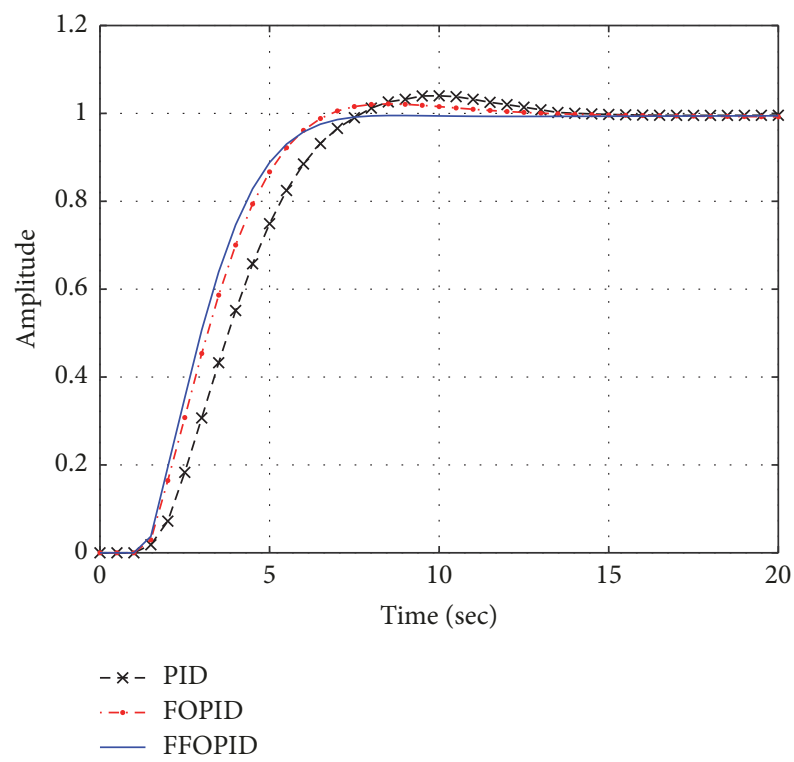

FIGURE 6: Step response of various controllers for pneumatic pressure control system.

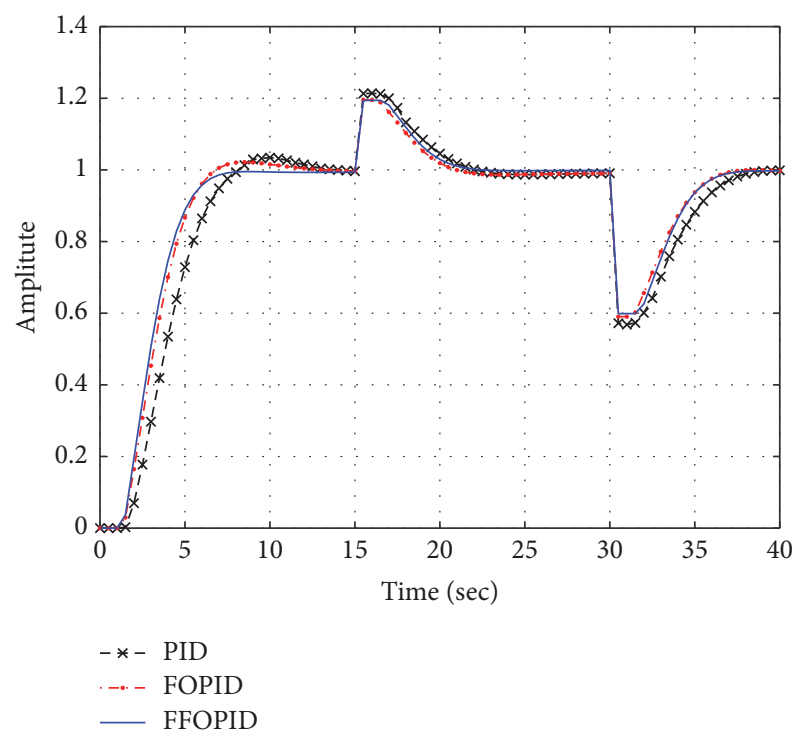

FIGURE 7: Load disturbances response of various controllers.

structure outperforms other two controllers at different test conditions for the pneumatic pressure system. The fuzzy logic system of FFOPID control structure enhances the controller

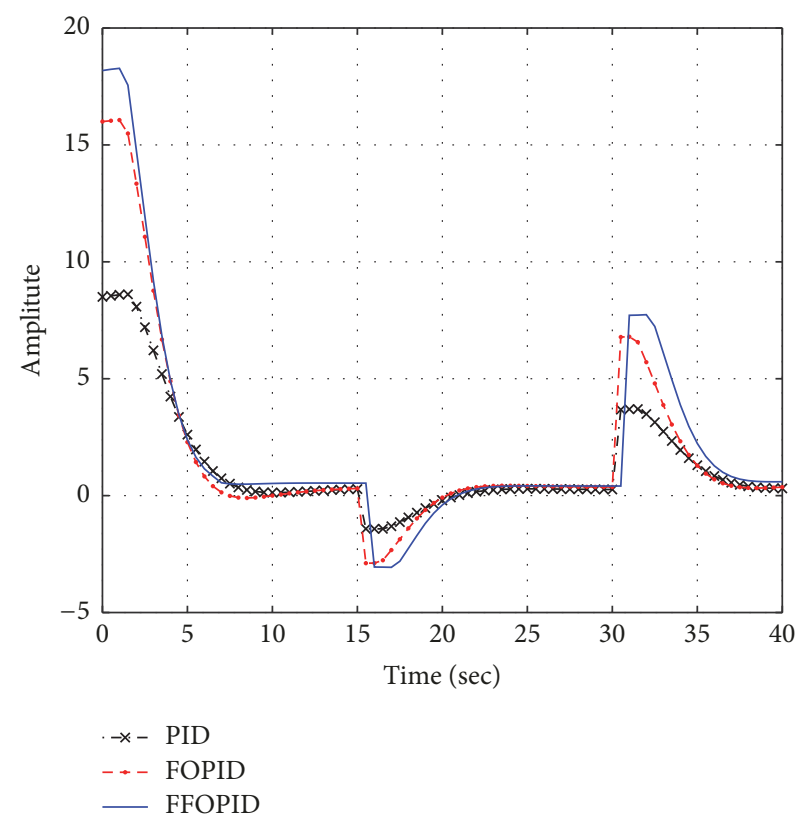

FIGURE 8: Control signal for load disturbances of various controllers.

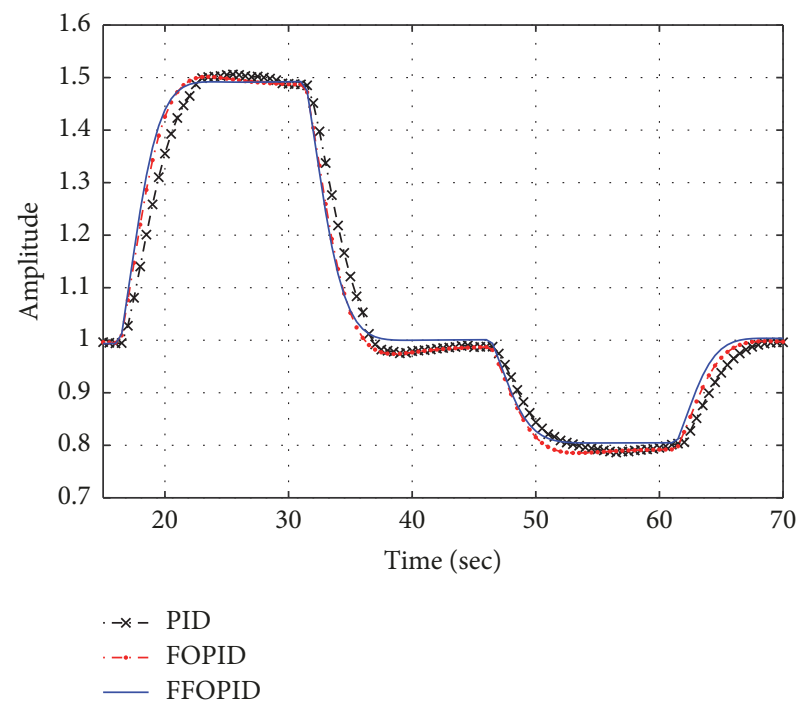

FIGURE 9: Change in set-point response of various controllers.

performance through online gain tuning mechanism. The robustness and adaptability of the proposed control scheme were also studied under load disturbance circumstances. From the results, it is observed that the FFOPID control scheme is better for pressure control application. Comparative studies are also made with conventional PID and FOPID control scheme to validate the proposed method. Moreover, this control scheme is simple, is effective, and could be a better alternative to the existing conventional control scheme. This study can be extended in future to digital algorithm and implemented using microprocessor or microcontroller. 


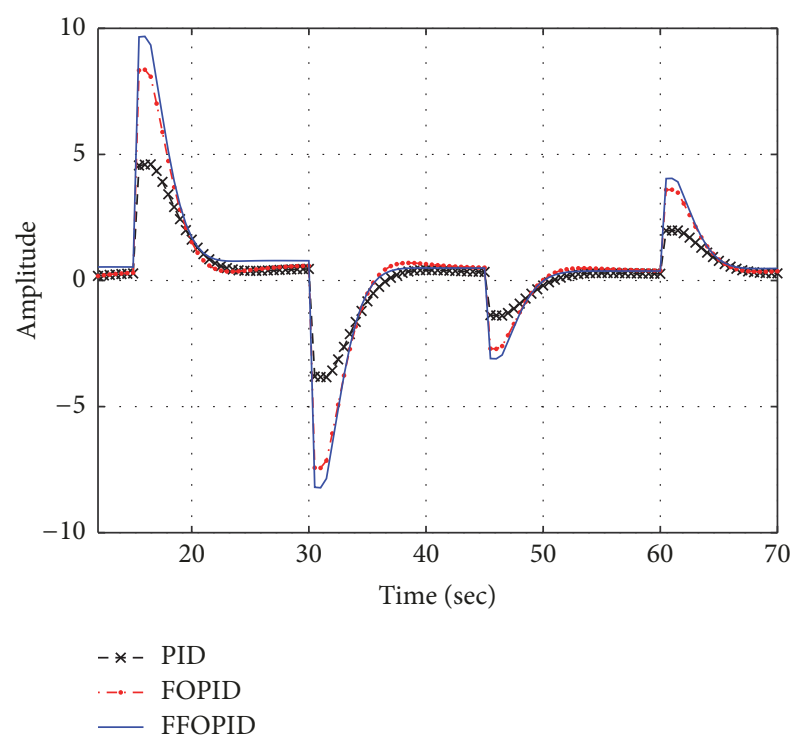

Figure 10: Control signal for change in set point of various controllers.

\section{Conflicts of Interest}

The authors declare that they have no conflicts of interest.

\section{Acknowledgments}

This project was supported by the Deanship of Scientific Research at Prince Sattam Bin Abdulaziz University under the Research Project no. 2016/01/6637.

\section{References}

[1] K. B. Oldham and J. Spanier, Fractional Calculus: Theory and Applications of Differentiation and Integration to Arbitrary Order, Academic Press, New York, NY, USA, 1974.

[2] K. S. Miller and B. Ross, An Introduction to the Fractional Calculus and Fractional Differential Equations, A Wiley-Interscience Publication, John Wiley \& Sons, New York, NY, USA, 1993.

[3] A. Atangana and D. Baleanu, "New fractional derivatives with non-local and non-singular kernel: Theory and application to heat transfer model," THERMAL SCIENCE, vol. 20, no. 2, pp. 763-769, 2016.

[4] I. Petras, L. Dorcak, and I. Kostial, "Control quality enhancement by fractional order controllers," Acta Montanistica Slovaca, vol. 3, pp. 143-148, 1998.

[5] N. M. F. Ferreira and J. A. T. Machado, "Fractional-order hybrid control of robotic manipulators," in Proceedings of the 11th International Conference on Advanced Robotics, pp. 393-398, Coimbra, June 2003.

[6] A. Kailil, N. Mrani, M. M. Touati, S. Choukri, and N. Elalami, "Low Earth-orbit satellite attitude stabilization with fractional regulators," International Journal of Systems Science, vol. 35, no. 10, pp. 559-568, 2004.

[7] C. Ma and Y. Hori, "The application of fractional order control to backlash vibration suppression," in Proceedings of the 2004 American Control Conference (AAC), pp. 2901-2906, usa, July 2004.
[8] D. Xue, C. Zhao, and Y. Chen, "Fractional order PID control of A DC-motor with elastic shaft: A Case Study," in Proceedings of the American Control Conference, pp. 3182-3187, Minneapolis, Minn, USA, June 2006.

[9] K. Erenturk, "Fractional-order $\mathrm{PI}^{\lambda} \mathrm{D}^{\mu}$ and active disturbance rejection control of nonlinear two-mass drive system," IEEE Transactions on Industrial Electronics, vol. 60, no. 9, pp. 38063813, 2013.

[10] P. Rastogi, S. Chatterji, and D. S. Karanjkar, "Performance analysis of fractional-order controller for $\mathrm{pH}$ neutralization process," in Proceedings of the 2012 2nd International Conference on Power, Control and Embedded Systems, ICPCES 2012, India, December 2012.

[11] K. M. Passino and S. Yurkovich, Fuzzy-Control, Wesley Longman, California, USA, 1998.

[12] M. Vahedpour, A. R. Noei, and H. A. Kholerdi, "Comparison between performance of conventional, fuzzy and fractional order PID controllers in practical speed control of induction motor," in Proceedings of the 2nd International Conference on Knowledge-Based Engineering and Innovation, KBEI 2015, pp. 912-916, Iran, November 2015.

[13] N. Bouarroudj, B. Djamel, and F. Boudjema, "Tuning fuzzy fractional order PID sliding-mode controller using PSO algorithm for nonlinear systems," in Proceedings of the 2013 3rd International Conference on Systems and Control, ICSC 2013, pp. 797-803, Algeria, October 2013.

[14] G. Mann, B. Hu, and R. Gosine, "Analysis and performance evaluation of linear-like fuzzy PI and PID controllers," in Proceedings of the 6th International Fuzzy Systems Conference, pp. 383-390, Barcelona, Spain, 1997.

[15] I. Podlubny, Fractional Differential Equations, vol. 198 of Mathematics in Science and Engineering, Academic Press, San Diego, Calif, USA, 1999.

[16] Y. Q. Chen, I. Petráš, and D. Y. Xue, "Fractional order control-a tutorial," in Proceedings of the American Control Conference (ACC '09), pp. 1397-1411, June 2009.

[17] R. E. Gutiérrez, J. M. Rosário, and J. T. MacHado, "Fractional order calculus: basic concepts and engineering applications," Mathematical Problems in Engineering, vol. 2010, Article ID 375858, 19 pages, 2010.

[18] I. Petráš, Stability of Fractional-Order Systems with Rational Orders: A Survey Fractional Calculus Applied Analysis12, 2009, pp. 269-298.

[19] I. Petráš, “Tuning and implementation methods for fractionalorder controllers," Fractional Calculus and Applied Analysis, vol. 15, no. 2, pp. 282-303, 2012.

[20] L. Ljung, System Identification Toolbox TM Users Guide, MathWorks Co. Ltd, 2015.

[21] A. Tepljakov, E. Petlenkov, and J. Belikov, "FOMCON: a MATLAB toolbox for fractional-order system identification and control," International Journal of Microelectronics and Computer Science, vol. 2, no. 2, pp. 51-62, 2011.

[22] A. T. Azar, S. Vaidyanathan, and A. Ouannas, Fractional Order Control and Synchronization of Chaotic Systems, Springer, 2017.

[23] S. Ahmed, "Parameter and delay estimation of fractional order models from step response," in Proceedings of the IFAC 9th International Symposium on Advanced Control of Chemical Processes, vol. 48, pp. 942-947, Whistler, British Columbia, Canada, June 7-10, 2015.

[24] J. G. Ziegler and N. B. Nichols, "Optimum settings for automatic controllers," Transactions of the ASME, vol. 64, pp. 759-768, 1942. 
[25] C. Y. Quan, “Applied Fractional Calculus," in Proceedings of the American Control Conference-ACC2009, St. Louis, Missouri, USA, 2009.

[26] C. Junyi and C. Binggang, "Fractional-order control of pneumatic position servosystems," Mathematical Problems in Engineering, vol. 2011, Article ID 287565, 14 pages, 2011.

[27] S. Manabe, "The non-integer integral and its application to control systems," JIEE (Japanese Institute of Electrical Engineers) Journal, vol. 6, pp. 83-87, 1961.

[28] A. Oustaloup, F. Levron, B. Mathieu, and F. M. Nanot, "Frequency-band complex noninteger differentiator: characterization and synthesis," IEEE Transactions on Circuits and Systems I: Fundamental Theory and Applications, vol. 47, no. 1, pp. 25-39, 2000.

[29] M. A. Luersen and R. le Riche, "Globalized nelder-mead method for engineering optimization," Computers \& Structures, vol. 82, no. 23-26, pp. 2251-2260, 2004.

[30] R. K. Mudi and N. R. Pal, "A robust self-tuning scheme for PI- and PD-type fuzzy controllers," IEEE Transactions on Fuzzy Systems, vol. 7, no. 1, pp. 2-16, 1999. 


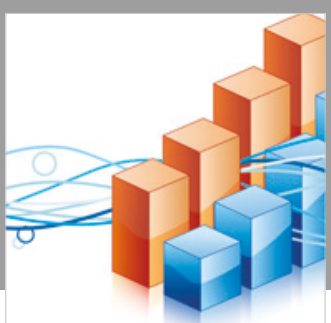

Advances in

Operations Research

\section{-n-m}
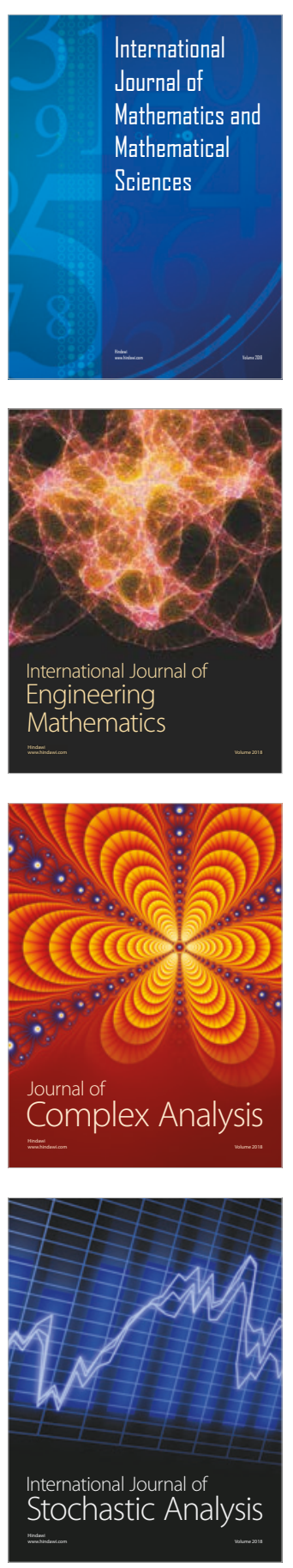
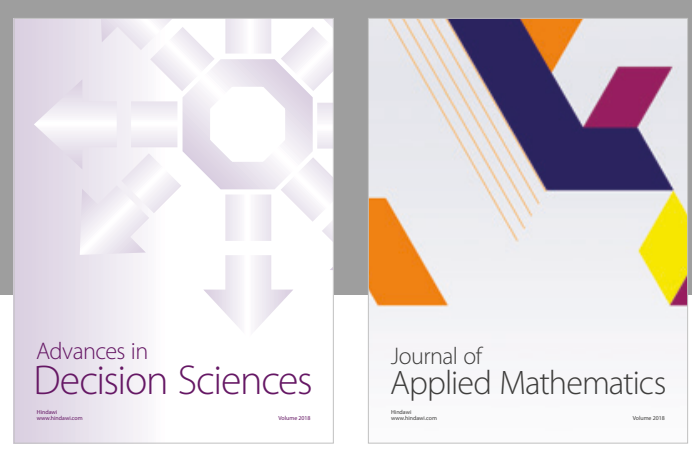

Journal of

Applied Mathematics
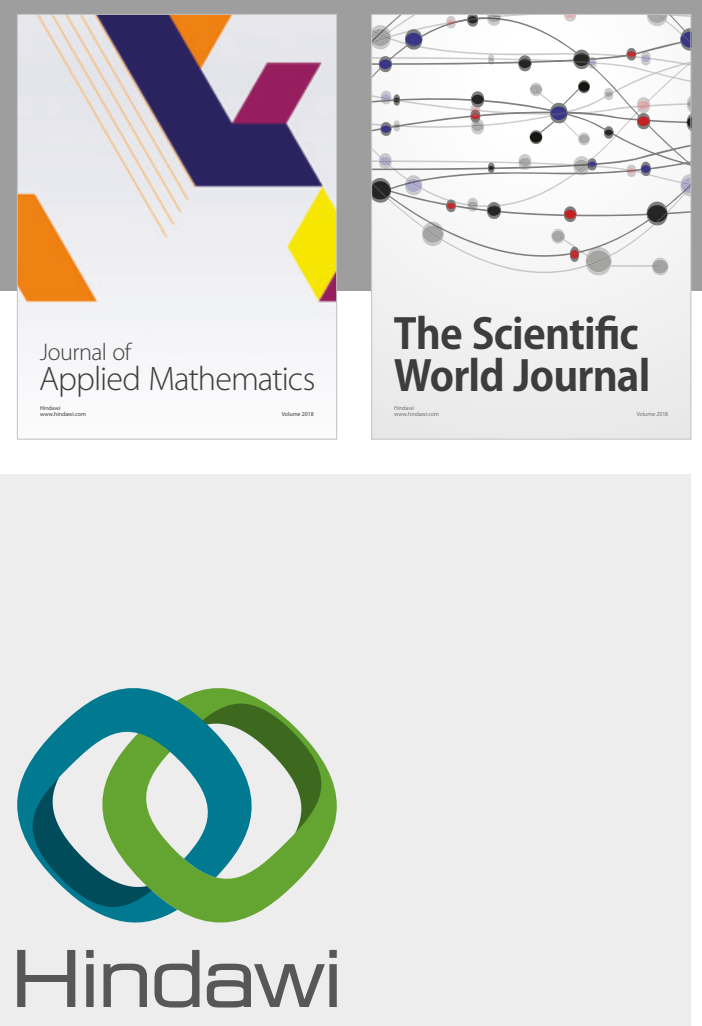

Submit your manuscripts at

www.hindawi.com

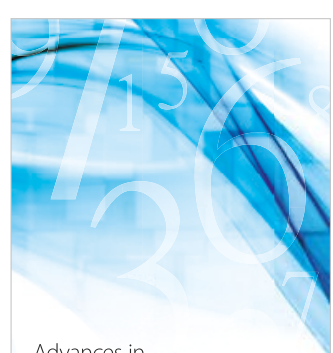

Advances in
Numerical Analysis
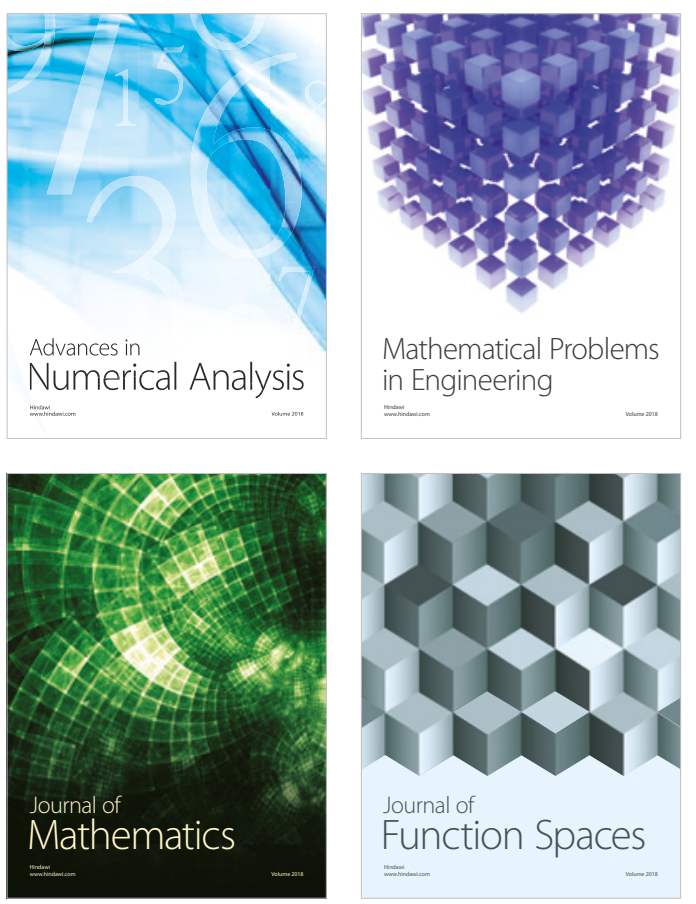

Mathematical Problems in Engineering

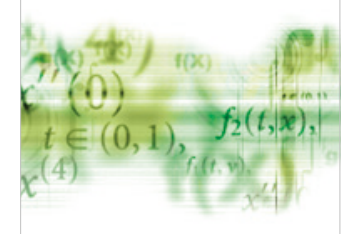

International Journal of

Differential Equations

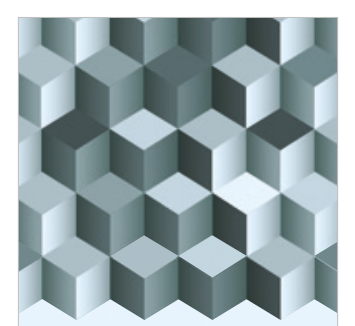

Journal of

Function Spaces

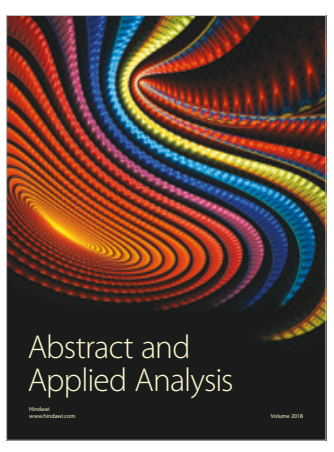

The Scientific

World Journal

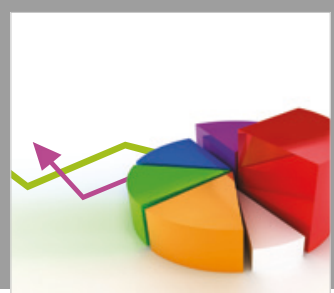

Journal of

Probability and Statistics
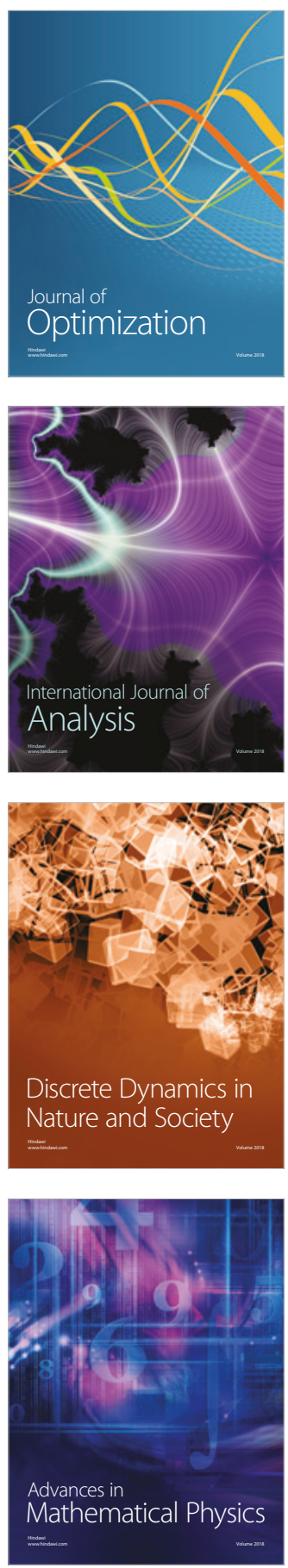